\title{
Climate change, Pacific climate drivers and observed precipitation variability in Tahiti, French Polynesia
}

\author{
M. Hopuare ${ }^{1,2, *}$, M. Pontaud ${ }^{2}$, J.-P. Céron ${ }^{3}$, P. Ortéga ${ }^{1}$, V. Laurent ${ }^{4}$ \\ ${ }^{1}$ GePaSud Laboratory, 98702 Tahiti, French Polynesia \\ ${ }^{2}$ CNRM GAME UMR 3589, Météo France/CNRS, 31057 Toulouse, France \\ ${ }^{3}$ Direction de la Climatologie, Météo France, 31057 Toulouse, France \\ ${ }^{4}$ Direction Inter Régionale de Polynésie Française, Météo France, 98702 Tahiti, French Polynesia
}

\begin{abstract}
This study addresses the low-frequency variability of precipitation and the detection of climate change over Tahiti, a small orographic island in French Polynesia in the tropical South Pacific. The analysis of new homogenized rainfall amounts over the period 1961-2011 shows no significant trend related to climate change, but highlights the interactions between ENSO, the South Pacific Convergence Zone (SPCZ) and rainfall during the latest positive phase of the Interdecadal Pacific Oscillation (IPO) (1977-1999). During this particular phase, the SPCZ is closer to Tahiti and induces positive large-scale precipitation. On interannual time scales, more frequent and strong El Niño events favour a northward SPCZ migration. This northern position causes a surface flux over Tahiti Island, which forces orographic precipitation on the windward side. During the negative phase of IPO, no clear link is established between SPCZ, ENSO and rainfall variability.
\end{abstract}

KEY WORDS: Rainfall variability · Climate change - ENSO - South Pacific Convergence Zone · SPCZ · Interdecadal Pacific Oscillation · IPO · Tahiti

\section{INTRODUCTION}

Situated in the middle of the Pacific Ocean, Tahiti $\left(\sim 17.5^{\circ} \mathrm{S}, 149.5^{\circ} \mathrm{W}\right)$, the biggest island of French Polynesia, enjoys a tropical climate. The island lies at the southeastern edge of the climatological South Pacific Convergence Zone (SPCZ). Spatio-temporal patterns of precipitation and related water resources in Tahiti are therefore very sensitive to the SPCZ's anomaly in intensity and location. Laurent et al. (2004) have shown that Tahiti's annual rainfall cycle is composed of 2 main seasons: the wet or warm season from November to April, during which precipitation amounts are the highest (and therefore this is the season of interest when looking at water resource management), and the dry or cooler season from May to October, characterized by lower amounts of rainfall. During the wet season, 2 main regimes prevail:
(1) precipitation associated with the presence of the SPCZ, and (2) orographic precipitation caused by moist air brought by the trade winds, which induce higher rainfall on the windward side of Tahiti. During the dry season, the SPCZ is reduced and confined to the western part of the basin, and the orographic rainfall signal produced by the southeast trade winds becomes the dominant regime.

Regarding the SPCZ, numerous studies have attempted to unravel the basic mechanisms that control its structure and variability, which remain only partly understood. Vincent (1994) showed that this convergence zone was present all year round and most strongly established in the austral summer. It consists of a zonal portion over the Pacific warm pool region and a diagonal portion extending along a northwestsoutheast axis towards French Polynesia (Streten 1973). The diagonal SPCZ climatology has been 
thought to depend on interactions with subtropical depressions (Hurrell \& Vincent 1987, Kiladis et al. 1989, Widlansky et al. 2011) and on the existence of a dry zone in the southeastern Pacific, induced by the Andes (Takahashi \& Battisti 2007). On shorter timescales, Lintner \& Neelin (2008) showed that the position of the SPCZ eastern margin was controlled by the zonal dry air inflow associated with trade wind strength. The SPCZ's zonal portion, on the other hand, is likely to be influenced by the SST gradients and the land-ocean distribution according to Kiladis et al. (1989). On intraseasonal timescales, the zonal portion experiences discrete pulses arising from the Madden-Julian Oscillation (MJO) (Matthews \& Li 2005). Using daily outgoing longwave radiation (OLR) records, Matthews (2012) carried out an analysis of the SPCZ variability in a multi-scale framework. He pointed out 2 modes of variability, the westward shifted SPCZ mode and the enhanced mode. He found that the mechanism behind the occurrence of those modes was the equatorward incursion of synoptic wave trains from the southern hemisphere subtropical jet into the westerly duct over the central and eastern equatorial Pacific (Trenberth 1991). The refraction of these waves leads to their diagonal tilt (northwest-southeast). The occurrence of these events can be viewed as a stochastic process. The probabilities of the event occurring at a given location are then modified by other, lower-frequency variations in the basic state, such as the MJO and ENSO. The SPCZ remains a challenge for global coupled models (Brown et al. 2011, 2013), which fail to reproduce a realistic feature.

Several studies (Trenberth 1976, Rasmusson 1985, Vincent 1994, Folland et al. 2002, Vincent et al. 2011, Lorrey et al. 2012) have shown that El Niño (La Niña) events tend to favour a northeastward (southwestward) displacement of the SPCZ. Typically, the South Pacific's basic state is known to vary on interannual time scales, particularly with respect to ENSO. A recent study by Murphy et al. (2014) focused on the diversity of impacts caused by different types of ENSO events on Pacific island climates. During an El Niño event, i.e. a warm phase of ENSO, the region of high SSTs of the western Pacific expands eastward beyond the date line and the SPCZ is shifted equatorward (northeast). This shift favours the presence of the SPCZ in the vicinity of French Polynesia, suggesting positive rainfall anomalies in Tahiti. Conversely, during a La Niña event or a cold ENSO phase, the mean convection over the 'warm pool' region is enhanced and the SPCZ is displaced poleward (southwest). This tilt causes the SPCZ to be located further away from French Polynesia, implying negative rainfall anomalies in Tahiti.

Past signatures of climate change in the Pacific islands through the analysis of temperature and rainfall trends have been the topic of many published studies (Folland et al. 2003, Griffiths et al. 2003, Murphy \& Timbal 2008, Jovanovic et al. 2012, McGree et al. 2014, Whan et al. 2014), which illustrate a joint effort to improve knowledge and understanding on the subject. Griffiths et al. (2003) found that rainfall trends in the South Pacific were spatially consistent east of the dateline. These trends were associated with a northeastward migration of the diagonal SPCZ from the late 1970s through to the 1990s, associated with a change to a positive Interdecadal Pacific Oscillation (IPO) phase. Folland et al. (2003) also confirmed the roles of the IPO and the SPCZ for temperature variability and trends for South Pacific islands. They pointed out that, to the northeast of the SPCZ, decadal increases in annual temperature have only been widely observed since 1970. McGree et al. (2014), using longer and more reliable rainfall records, encompassing the recent switch to a negative IPO phase since 1999, computed trends over 19812011. From trends in total rainfall, they found that it has become wetter to the southwest of the mean SPCZ position, whereas northeast of the SPCZ and in the central tropical Pacific (east of about $160^{\circ} \mathrm{E}$ ), it has become drier. Focusing on Australia's remote islands, Jovanovic et al. (2012) analysed homogenized time series and showed that the overall temperature increase at all island sites fitted the warming of SST in their vicinity, and was consistent with larger-scale warming trends that affect the globe. Murphy \& Timbal (2008) reviewed southeastern Australia's temperature and rainfall variability and change over the dry decade of 1997-2006. They argued that atmospheric circulation features (the southern annular mode and the subtropical ridge) may have played a role in the rainfall decline, and that there was a likely impact of enhanced greenhouse gas concentrations on the climate of southeast Australia, at least on temperature. Using climate models, many studies analysed the evolution of the dominant features of the Pacific under greenhouse warming. Cai et al. (2012) and Widlansky et al. (2013) revealed that the SPCZ would likely experience more drastic equatorward migrations. Power \& Smith (2007) and Power \& Kociuba (2011) were more interested in the changes regarding ENSO and the Walker Circulation. Their results imply a weakening of the Walker Circulation in response to global warming, whereas no consensus has emerged in cli- 
mate models regarding a change in ENSO behaviour.

The objectives of the present study were: (1) to properly characterize the main precipitation patterns in Tahiti associated with the seasonal cycle and with lower-frequency basin-wide oscillations using a new and high-quality data set; and (2) to look for any climate trend signature.

\section{DATA AND METHODS}

\subsection{Precipitation records}

We used monthly precipitation data from the meteorological service of French Polynesia. The homogenization procedure 'Prodige' described by Caussinus \& Mestre (2004) was applied to a total of 9 stations on the island of Tahiti in order to adjust the inhomogeneities due, for example, to changes in the conditions of measurement, relocation of the weather station or modification of the environment. This technique can only be used if at least 5 neighbouring stations are available and are climatologically wellcorrelated with each other over a minimum period of 16 yr. These criteria are met for only a few stations on the island of Tahiti and 1 station on Moorea. Nevertheless, they provided high-quality data records for the period 1961-2011. The 9 stations are shown in Fig. 1. They are not regularly distributed, since the majority of them are located on the western part of the island and mainly on the coast. The stations on the north and west coasts are highly correlated with each other (no less than 0.8) and so are the southern stations with each other (no less than 0.6); the correlation coefficient drops to 0.4 when considering a northern station and the southernmost station.

\subsection{ENSO, IPO and SPCZ indices}

The Niño3.4 index is used to characterize ENSO variability (available from the NOAA Climate Prediction Center website: www.cpc.ncep.noaa.gov/products/ analysis_monitoring/ensostuff/ensoyears.shtml). The index values corresponded to ERSST v. 3b SST anomalies in the region $\left(5^{\circ} \mathrm{N}-5^{\circ} \mathrm{S}, 120^{\circ} \mathrm{W}-170^{\circ} \mathrm{W}\right)$ based on centred $30 \mathrm{yr}$ base periods, updated every 5 years. Warm and cold episodes were defined when the threshold of $\pm 0.5^{\circ} \mathrm{C}$ was reached. The period considered for this study matches the availability of the observed data, that is to say 1961-2011.

The unfiltered monthly IPO index was created by projecting unfiltered monthly SSTs from the HadISST data set (Rayner et al. 2003) onto the second low-frequency filtered global covariance EOF of SST for the period 1891-2005 calculated by Parker et al. (2007). The monthly values from 1871 to 2008 were provided by the Met Office. The monthly values were then annually averaged and smoothed using a

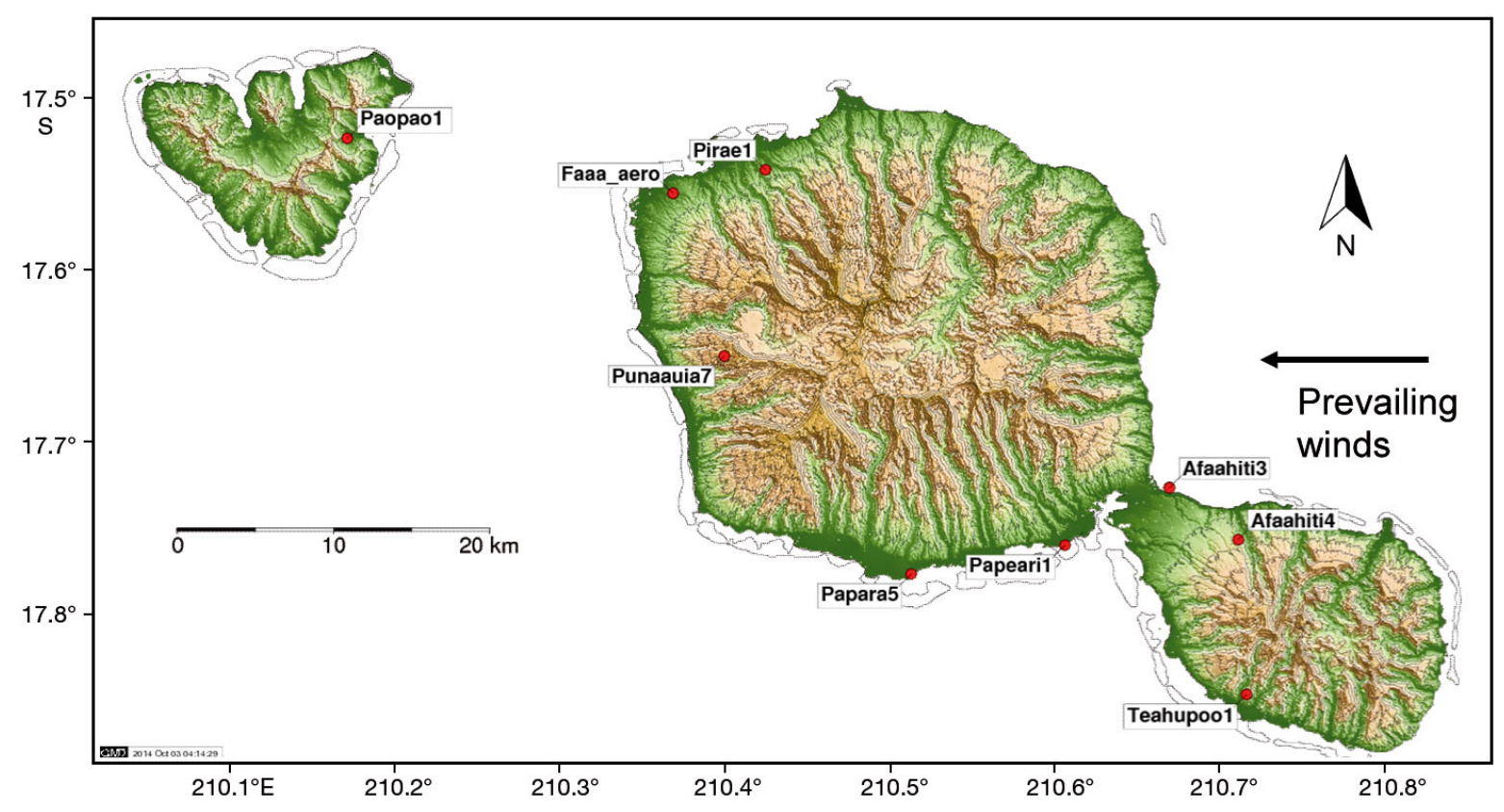

Fig. 1. Rainfall gauge positions: Tahiti (8 stations) and Moorea (leftmost island; 1 station). Station names correspond to the names of the small towns, except Faaa_aero, which stands for the airport of Tahiti 
13 yr low-pass filter to obtain the IPO index time series.

For the purpose of the study, we defined an index accounting for the latitudinal displacements of the SPCZ in the vicinity of Tahiti, based on the precipitation maximum. Usually, such indexes are derived from the maximum of low-level convergence (Folland et al. 2002) or based on mean sea-level pressure differences (Salinger et al. 2014). In fact, each variable would imply a slightly different location of the SPCZ. Thus, Kiladis et al. (1989) pointed out that the precipitation maximum lies north of the maximum of low-level convergence. In this study, we preferred to build another index, adapted to Tahiti, that would account for the large-scale precipitation variations associated to the displacements of the SPCZ. The SPCZ position proxy used in this study was taken as the latitude of the precipitation maximum along the meridian that crosses the island of Tahiti. It was calculated using the $0.5^{\circ} \times 0.5^{\circ}$ interpolated Global Precipitation Climatology Project (GPCP) data set (Adler et al. 2003). This value was used to compute the SPCZ latitude index (called SPLAT hereinafter). Basically, for each month, the SPLAT value was taken as the average of the latitude of the maximum rainfall between $5^{\circ}$ and $30^{\circ} \mathrm{S}$ at each longitude in the $145^{\circ}-155^{\circ} \mathrm{W}$ band. This quantity was then normalized based on the period 1979-2010 to obtain the SPLAT index. Anomalous northward (southward) SPCZ movements were characterized by SPLAT values greater (less) than or equal to $+(-) 0.5$ standard deviations $(\sigma)$. The neutral SPCZ position encompassed SPLAT values in the range $]-0.5 \sigma_{,}+0.5 \sigma[$. Unlike Niño3.4 and the IPO index, SPLAT only partially covered the period of available rainfall observations (1979-2010) in accordance with the GPCP data set.

In order to account for the east-west movements of the SPCZ, the SPCZ longitude index was computed. A temporal analysis of the GPCP data set for the South Pacific from 0 to $30^{\circ} \mathrm{S}$ helped to define the rainfall threshold of $5 \mathrm{~mm} \mathrm{~d}^{-1}$ that was encountered alternately to the east and west of Tahiti depending on the phase of ENSO. The easternmost longitude at which this threshold was met was taken as a proxy for the longitude of the SPCZ near Tahiti.

\subsection{Analysis tools}

The main features of the precipitation signal over Tahiti were extracted by applying an EOF analysis. This analysis was first applied to monthly rainfall (covariance matrix) in order to account for all the modes of variability including the seasonal cycle. Then, in a second phase, the EOF was applied to normalized monthly rainfall (correlation matrix) in order to isolate the modes of variability that emerged after the removal of the seasonal cycle. Composites, consisting of the average of rainfall anomalies on dates referring to specific ENSO or IPO phases, were computed to assess the impacts of these oscillations on Tahiti's rainfall. The impact of climate change on Tahitian rainfall during 1961-2011 was estimated using the temporal optimal detection method (TOD) described by Ribes et al. (2010). Basically, TOD can be seen as a refinement of trend analysis, which accounts for a potential non-uniformity of climate change over the area of interest.

\section{SEASONAL CYCLE}

The first mode of variability of Tahiti's monthly precipitation is the seasonal cycle. The first principal component (PC1) explains $89 \%$ of the total variance, while the eigenvector shows in-phase rainfall variations across all stations (Fig. 2a). The spectral analysis of the PC1 time series is shown in Fig. 2b and reveals the importance of the seasonal cycle for precipitation variability at the monthly scale. According to EOF1, all stations register more (less) precipitation during the austral summer (winter), in agreement with the location of the SPCZ near (away from) Tahiti as described by Vincent (1994). However, the stations on the lee side tend to have a weaker intensity compared to the windward stations (Fig. 2a), suggesting that the seasonal cycle signal also has an orographic component. This assumption is consistent with the $10 \mathrm{~m}$ wind speed and direction climatology derived from ERA-Interim reanalysis. Fig. 3 shows the dominance of an eastern wind flow that varies slightly from northeast during DJF to southeast during JJA and SON. The orographic response is particularly marked during austral winter (JJA) as the southeastern trade winds are not obstructed by the presence of the SPCZ.

The seasonal distribution of rainfall for the spatial average of the 9 stations is given in Fig. 4 a, along with the most contrasted stations (the driest: Faaa_aero, the wettest: Teahupoo1). The seasonal cycle is divided into 2 contrasted periods. The wet season runs from November to April, during which rainfall amounts are high and the orographic contrast is low. November and April are the transition months flanking the low-contrast period. The dry season 
a) EOF $189 \%$
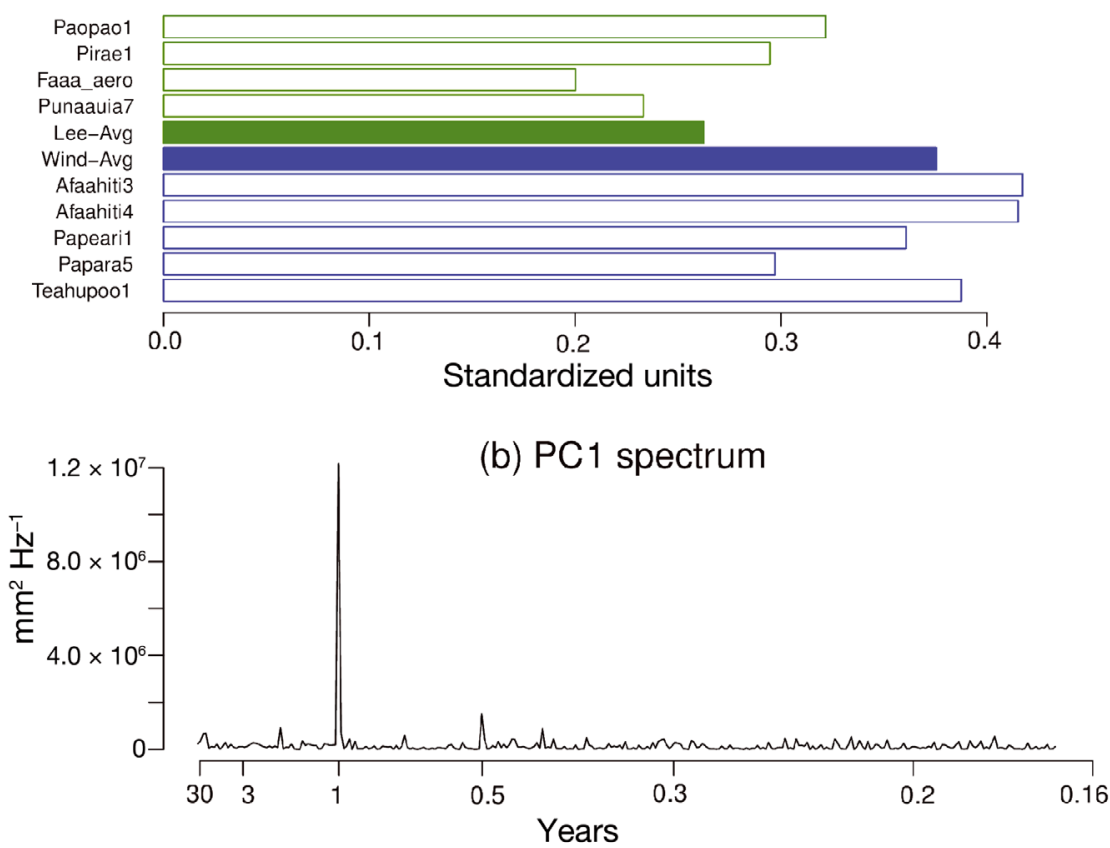

Fig. 2. First EOF on Tahiti's monthly total rainfall amounts for the period 1961-2011: (a) 1st eigenvector, windward stations (unfilled blue bars), leeward stations (unfilled green bars), windward stations average (filled blue bar), leeward stations average (filled green bar); (b) PC1 power spectrum extends from May to October and is defined by reduced precipitation consistent with the departure of the SPCZ. The seasonal cycle of precipitation is in agreement with the $10 \mathrm{~m}$ wind climatology displayed in Fig. 3. In the absence of large-scale precipitation brought by the SPCZ in austral summer, the wind flow has a more important effect on the rainfall signal. Fig. 4b indeed reveals this enhanced contrast between windward stations and leeward stations for the dry season. Rainfall amounts are spatially averaged over windward stations and then over leeward stations, and the windward minus leeward values are plotted. The southeasterly wind regime induces higher amounts of rainfall on the windward side from April to November. Then, the orographic contrast is reduced from December to March, likely caused by the proximity of the SPCZ, which inhibits the southeastern flow. These results are consistent with the analysis of Laurent et al. (2004).
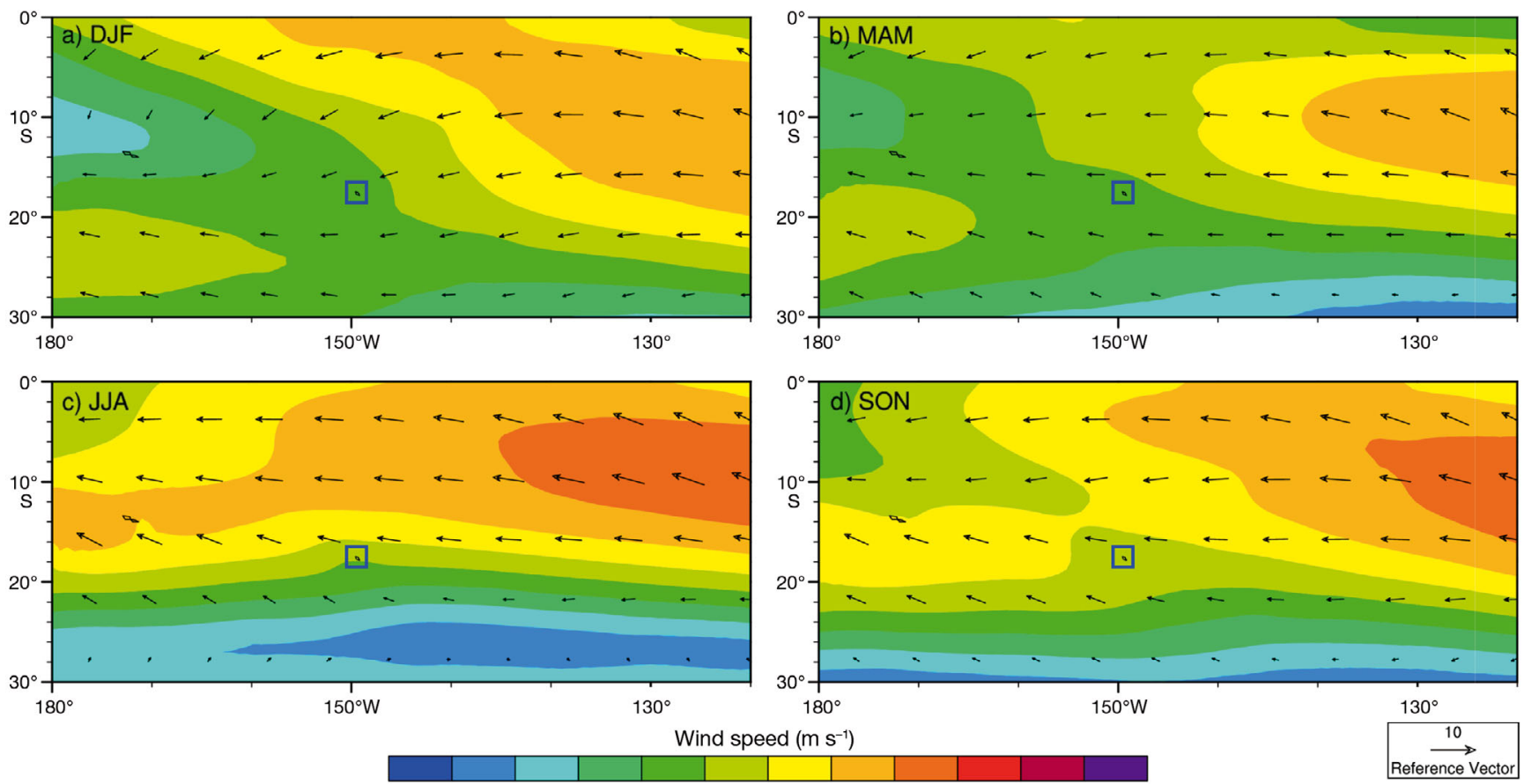

Fig. 3. ERA-Interim $10 \mathrm{~m}$ wind in $\mathrm{m} \mathrm{s}^{-1}$ for 1979-2010: (a) DJF mean, (b) MAM mean, (c) JJA mean, (d) SON mean. The small box (blue outline) shows the location of Tahiti 

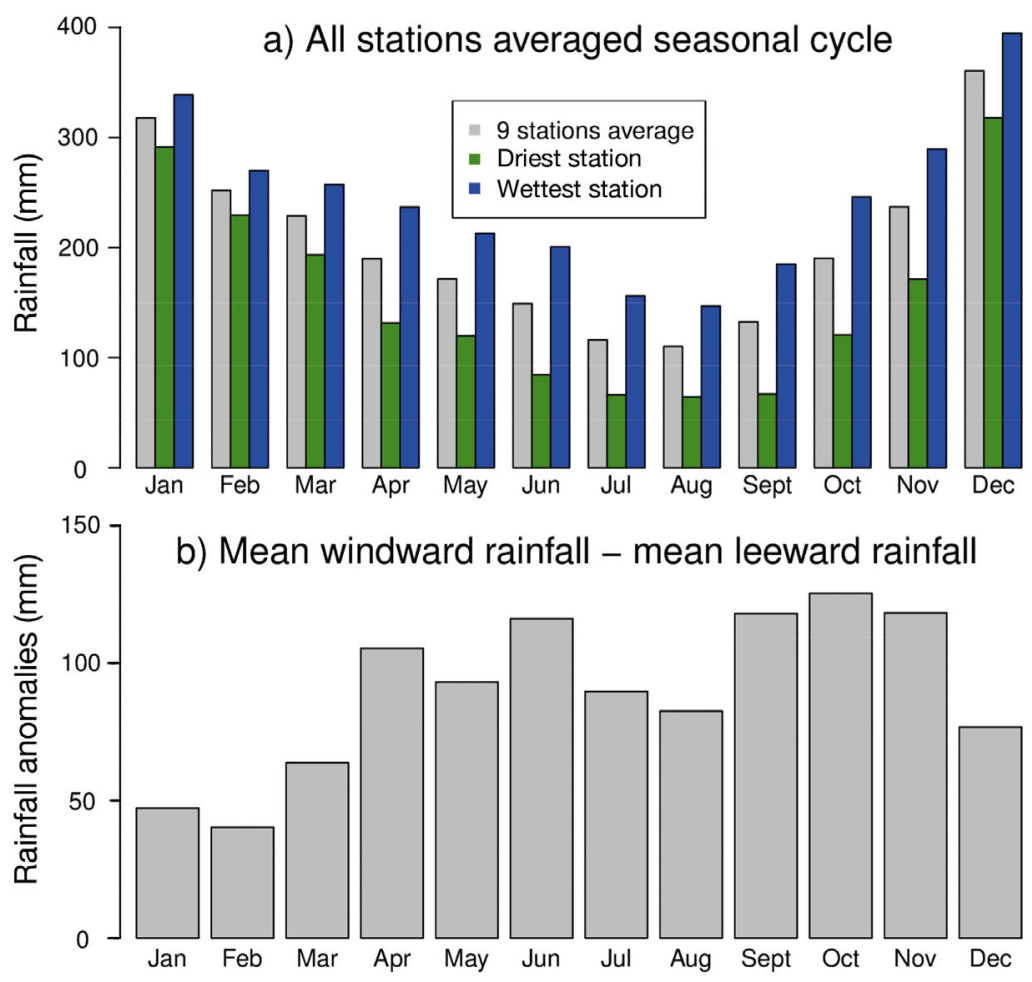

Fig. 4. (a) Rainfall seasonal cycle of the spatial average of all 9 stations, the driest station (Faaa_aero), and the wettest station (Teahupoo1). (b) Averaged windward station amounts minus averaged leeward station amounts. Monthly means were computed over the period 1961-2011

\subsection{EOF1: common behaviour of the stations}

The first eigenvector (Fig. 5a) shows that rainfall variability is dominated by in-phase anomalies, with $\mathrm{PC} 1<0$ (positive anomalies) characterizing the presence of deep convection on the island. The PC1 time series (Fig. 5b) has large negative peaks accounting for strong 'in-phase' positive rainfall anomalies, while weaker positive peaks refer to weak negative rainfall anomalies. The positive rainfall anomalies are less frequent than the negative ones, as they represent $39.9 \%$ of the time series, but they are characterized by intense episodes (strong negative peaks). The results from the spectral analysis of the EOF1 time series are shown in Fig. 5c. They reveal important peaks at intra-annual time scales (around $9 \mathrm{mo}$ ), and also from 1.2 to $1.6 \mathrm{yr}$. Other peaks are also encountered in the interannual and interdecadal frequency bands. The major negative peaks in the PC1 time series (associated with in-phase heavy precipitation anomalies) visible for the years 1978, 1979, 1980 and 1981 explain the spectral peaks ranging from 9 mo to $1.6 \mathrm{yr}$, and performing the EOF analysis on the period 1982-

\section{NON-SEASONAL VARIABILITY}

The non-seasonal variability of Tahitian rainfall was assessed by applying an EOF decomposition to the monthly standardized precipitation (i.e. minus the monthly climatological mean and divided by the monthly climatological standard deviation). To better understand the impact of the ENSO phenomenon on precipitation, we performed the EOF on the wet season only (November-April) when the impact is the most significant. The EOF performed on DJF months gave similar results. The atmospheric signature of the IPO is also known to be highest during austral summer (Salinger et al. 2001). In addition to this, many studies (Meehl 1987, Vincent 1994, Folland et al. 2002) have revealed that the SPCZ is most developed at this time of the year.

The first 2 EOFs accounted for, respectively, 70 and $14 \%$ of the total variance. They are displayed in Fig. 5. EOF1 shows the common behaviour of the stations that experience anomalous positive and negative precipitation alternately. The second EOF, on the other hand, underlines opposite behaviour between windward and leeward stations, hence an orographic response.
2011 only reduced those near-annual spectral peaks and slightly changed the frequency pattern (not shown). In fact, those particular years fell within the beginning of the positive phase of the IPO. Griffiths et al. (2003) found that stations located from 180 to $155^{\circ} \mathrm{W}$ experienced a greater number of abrupt changes in the extreme climate than anywhere else in the South Pacific, and the significant abrupt changes in extreme rainfall occurred in the late 1970s or early 1980s. The EOF performed on 9 stations of Tahiti confirmed Griffiths' conclusions. According to Salinger et al. (2001), the islands to the northeast of the SPCZ (like Tahiti) registered higher annual amounts during the positive phase of the IPO with respect to the negative phase, along with higher annual surface temperature and lower mean sea-level pressure. The PC1 time series was significantly correlated with the IPO at -0.40 , and this value increased after low-pass filters were applied. It reached -0.92 with a 13 yr low-pass filter on PC1, as applied for the computation of the IPO index, but is not statistically significant at the $5 \%$ level.

The first EOF therefore indicates that Tahitian rainfall is affected by the IPO, which controls the SPCZ mean location (Salinger et al. 2001, Folland et 

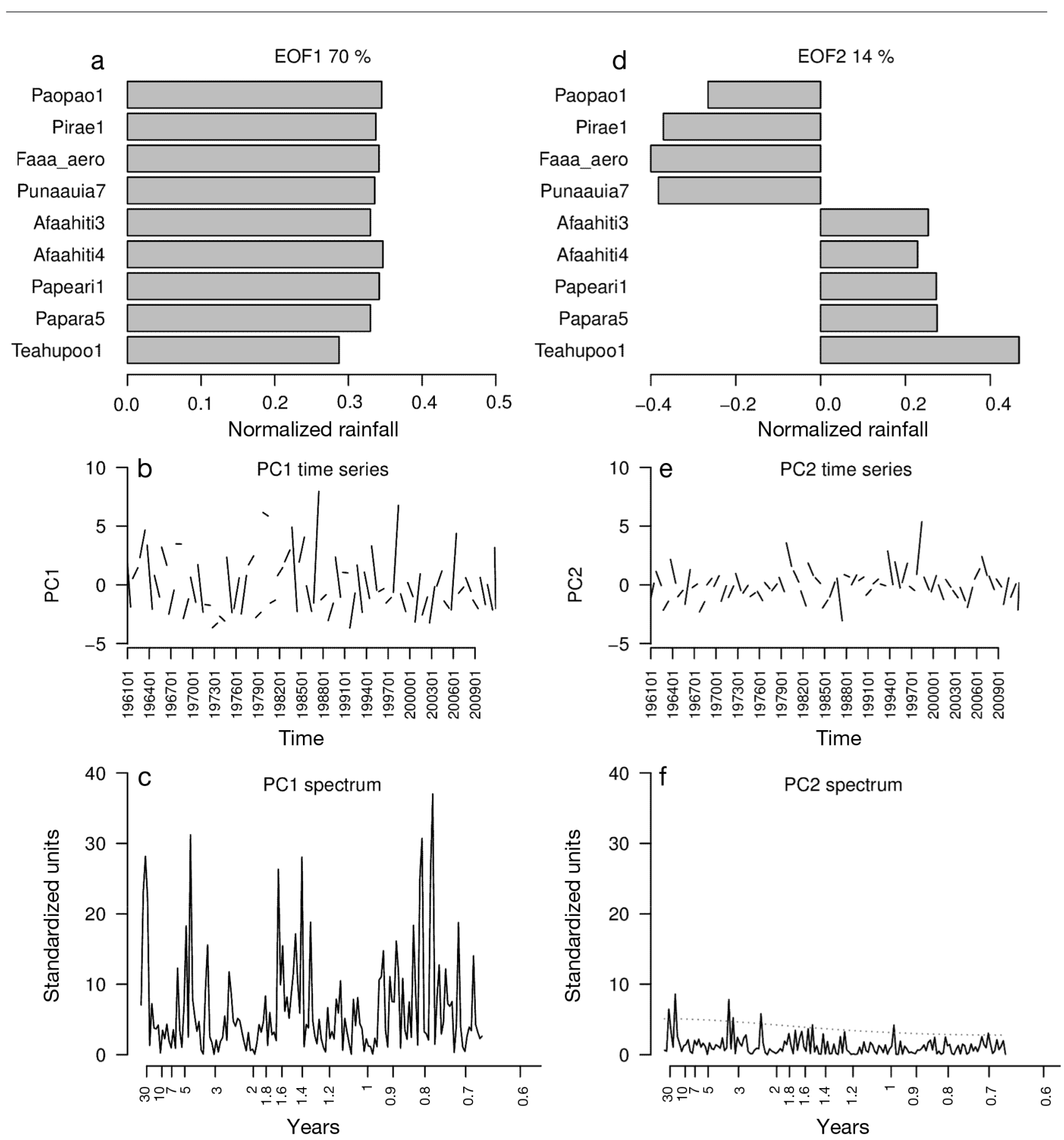

Fig. 5. EOF1 and EOF2 of Tahiti's monthly normalized precipitation (Nov-Apr) for the period 1961-2011. (a) 1st eigenvector, (b) PC1 time series, (c) PC1 power spectrum, (d) 2nd eigenvector, (e) PC2 time series and (f) PC2 power spectrum. Gaps in the time series (b,e) correspond to months May-Oct. The 95\% confidence limit red noise spectrum (dotted line) is plotted in (f)

al. 2002). During a positive IPO phase, the SPCZ is shifted to the northeast of its climatological position as pointed out by Folland et al. (2002), and directly impacts precipitation in Tahiti. This was effectively the case in our data set: the SPLAT index and PC1 time series were smoothed with a 5 yr low-pass filter in order to reduce the interannual fluctuations. The filtered SPLAT index was correlated with the IPO up to 0.50. Additionally, the filtered PC1 time series was correlated with the filtered SPLAT index to -0.66 . Finally, the correlation coefficient between the IPO and the filtered PC1 time series was -0.69 . The correlations were computed over a common period of 1981-2002 and are statistically significant at the 5\% level. The correlation between the IPO and the $13 \mathrm{yr}$ low pass filtered SPLAT would be very helpful to 
confirm the relationship between these two and EOF1 but, unfortunately, the SPLAT time series was too short to allow reliable correlation coefficients to be computed. The SPLAT index started in 1979 with satellite observations and the IPO index ends in 2008 (updated by the Met Office Hadley Center in 2008). Studying daily rainfall data in the South Pacific, Griffiths et al. (2003) argued that the displacement of the diagonal portion of the SPCZ on decadal time scales affected not only mean precipitation but also the daily rainfall extreme, suggesting an enhancement of the activity of the SPCZ as well. Although our analysis was based on monthly data, the intense rainfall episodes of 1978, 1979, 1980 and 1981, characterizing the presence of a highly active SPCZ in the vicinity of Tahiti, support their theory.

As for the relationship between EOF1 and the ENSO phenomenon, the correlation with the Niño3.4 index was weak $(-0.26)$, although the major spectral peak at 5 yr suggested an interannual modulation. This was easily deduced from the PC1 time series, the major peaks of which refer to the neutral ENSO state of 1978-1981. EOF1 appeared to be more linked to the SPCZ position, with -0.45 correlation with SPLAT (unfiltered time series), itself controlled on interdecadal scales by the IPO (Folland et al. 2002). The SPCZ's position is also known to be driven by ENSO on interannual timescales, as demonstrated by Vincent et al. (2011), and this effect will be discussed further in Section 4.3.

The rainfall regime depicted by EOF1 shows a behaviour common to all the stations, with interdecadal, interannual and intraseasonal modulation.

\subsection{EOF2: Orographic forcing}

The second eigenvector (Fig. 5d) shows the orographic component of the nonseasonal precipitation signal, where the pattern corresponds to an orographic dipole. $\mathrm{PC} 2>0(\mathrm{PC} 2<0)$ refers to positive rainfall anomalies on the windward side (lee side) of Tahiti. Positive and negative PC2 months each represent $50 \%$ of the time series (Fig. 5e). The results from the spectral analysis of the PC2 time series are displayed in Fig. 5f. They reveal weaker peaks compared to the EOF1 spectrum, but the 3 major ones fall within the interannual and interdecadal frequency bands. The major positive peaks of $\mathrm{PC} 2$ refer to the strong Niños of 1982-83, 1991-92 and 1997-98, but other positive peaks correspond to moderate Niños or even to neutral ENSO events. Negative peaks, on the other hand, are related to La Niña events of 1983-84,
1995-96, 2000-01 and 2005-06, with 1 negative peak referring to the warm event of 1986-87. The PC2 time series is in slightly better agreement with the Niño3.4 index and SPLAT than that of PC1, but the correlation coefficients are not very high. Considering the common availability period of 1979-2010, we found a significant correlation (at the $5 \%$ level) of 0.75 between the SPLAT and Niño3.4 indices, 0.53 between the SPLAT index and EOF2, and 0.42 between Niño3.4 and EOF2.

The rainfall regime depicted by EOF2 showed an orographic pattern on Tahiti with interannual modulation. The interannual influence of ENSO on the SPCZ position and Tahitian rainfall will be described in Section 4.3.

\subsection{IPO, ENSO, SPCZ and rainfall relationships}

IPO and ENSO composites were computed in order to better understand the rainfall regimes derived from the EOF analysis.

Normalized rainfall composites were computed over the IPO positive phase (1977-1999) and negative phases (1961-1976 and 2000-2011). Fig. 6 shows that the positive IPO phase was associated with an increase in rainfall (NDJFMA) with respect to the 19612011 climatology, while negative IPO phases induced rainfall reductions. All stations exhibited common behaviour, confirming the role of the IPO on the variability mode depicted by EOF1. Averaging the latitude of the precipitation maximum near Tahiti (proxy for the SPCZ position) over each IPO phase indicated that it was located at $19^{\circ} \mathrm{S}$ during IPO+ and at $23^{\circ} \mathrm{S}$ during IPO-. The SPCZ, closer to Tahiti during the IPO positive phase, favoured large-scale precipitation all over the island (positive EOF1). The IPO composites also showed a slight orographic signature, with windward stations more impacted than leeward stations, suggesting a small signature of EOF2.

In a second step, 4 normalized rainfall composites were computed for strong Niños (Niño3.4 $>1, \sim 49$ cases $)$, moderate to weak Niños $(0.5<$ Niño3.4 $<1$, $\sim 32$ cases), strong Niñas (Niño3.4 $<-1, \sim 39$ cases) and moderate to weak Niñas $(-1<$ Niño3.4 $<-0.5$, $\sim 53$ cases). The results, displayed in Fig. 7, show that El Niño induces an orographic fingerprint in favour of the windward side (Fig. 7a,b) consistent with EOF2. For strong El Niño events, the orographic signal shows substantial positive anomalies on the south coast (windward side). For moderate El Niño, negative anomalies appear on the north coast (lee side). In the La Niña case, the strong events imply general 

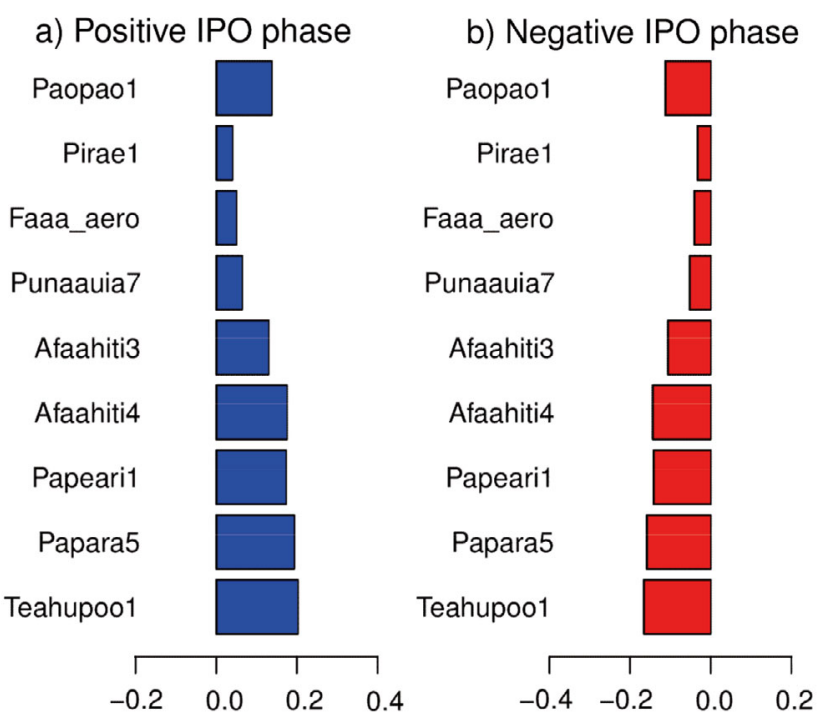

Fig. 6. Interdecadal Pacific Oscillation (IPO) composites: NDJFMA normalized precipitation ( $x$-axis quantifies normalized precipitation: $\frac{x-\bar{x}}{\sigma_{x}}$ ) averaged over (a) IPO positive phase (1978-1999) and (b) IPO negative phases (1961-1977 and 2000-2011)

drying (negative EOF1), while moderate events have an opposite orographic signal with wetter conditions on the north coast (negative EOF2).

In order to capture the relationship between ENSO, the IPO, the SPCZ position and the rainfall regimes, we plotted the 5 mo low-pass-filtered SPCZ latitude (near Tahiti) with respect to the 5 mo low-pass-filtered Niño3.4 index while also displaying the IPO phase in Fig. 8a. In order to picture the ENSO-related eastwest movements of the SPCZ, the Niño3.4 index is plotted against the SPCZ longitude index in Fig. 8b.

Fig. 8 shows, first, that strong El Niño events are mostly encountered during the positive phase of the IPO. And, among the El Niño events, there seems to be a quasi-linear response of the latitude and longitude of the SPCZ, the northward and eastward displacements of the SPCZ increasing along with the value of Niño3.4. The associated rainfall patterns in Tahiti exhibit 2 responses to strong and moderate El Niño:

- Strong El Niño events occur only during the positive IPO phase and, together, they induce a significant northward (about $12^{\circ} \mathrm{S}$ and higher) and eastward shift $\left(142^{\circ} \mathrm{W}\right)$ of the SPCZ. The northeast position of the SPCZ implies the departure of the large-scale convective precipitation over Tahiti, probably changing the wind flow, which induces orographic rainfall on the south coast of Tahiti (positive EOF2). a) Strong El Niño

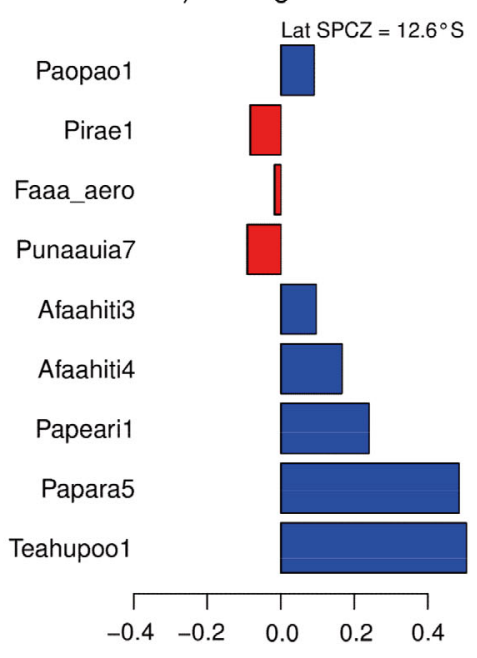

c) Strong La Niña

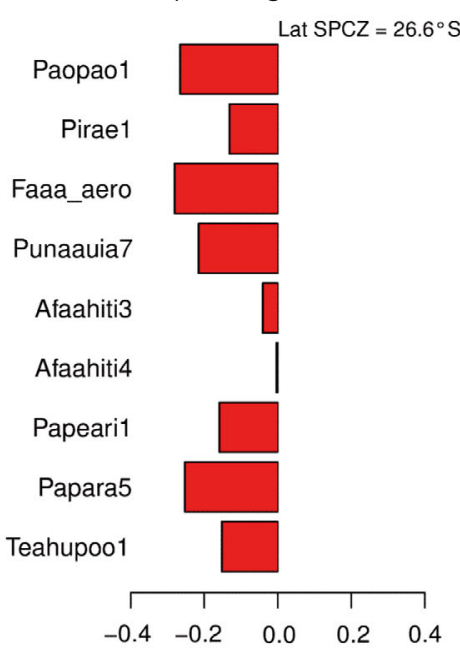

b) Moderate EI Niño

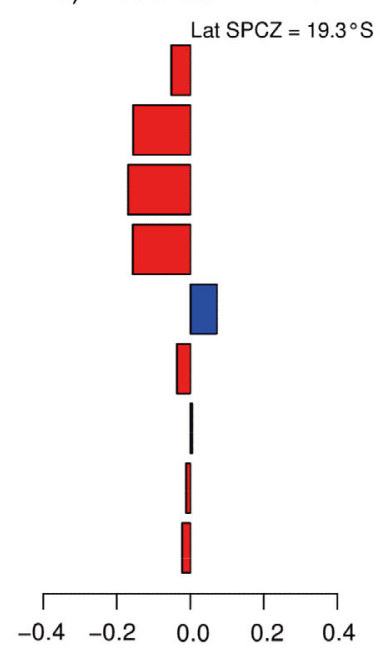

d) Moderate La Niña

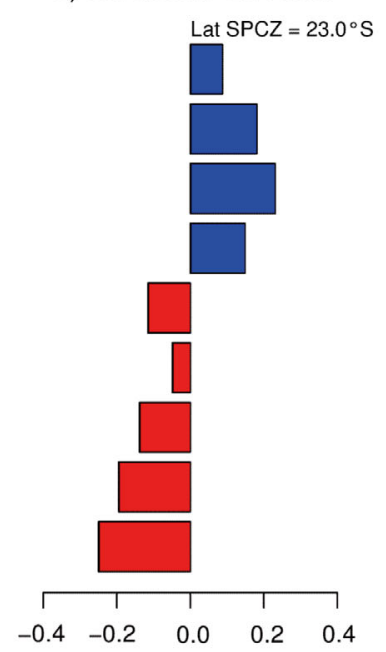

Fig. 7. ENSO composites: normalized rainfall averaged over NDJFMA months corresponding to: (a) Niño3.4 > 1: strong Niños, (b) $0.5<$ Niño3.4 < 1:moderate Niños, (c) Niño3.4<-1: strong Niñas and (d) $-1<$ Niño3.4 < -0.5 : moderate Niñas

- The occurrence of moderate El Niño events does not seem to be affected by the phase of the IPO. The mean latitude of the SPCZ is about $19^{\circ} \mathrm{S}$, with a mean longitude of $151^{\circ} \mathrm{W}$, which favours negative rainfall anomalies on the north coast. However, the small number of events makes it difficult to infer confident linkages.

The robust linkages between IPO, ENSO, SPCZ and precipitation derived from this study and that would be of interest for water resource management are:

- the IPO-related displacements of the SPCZ that imply higher (lower) than normal rainfall amounts for the positive (negative) phase 
a) SPCZ North-South migrations

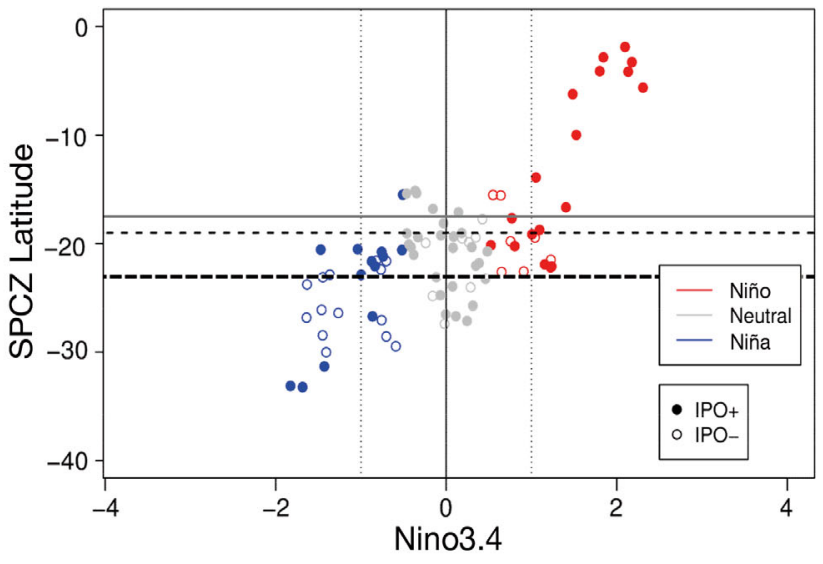

b) SPCZ East-West migrations

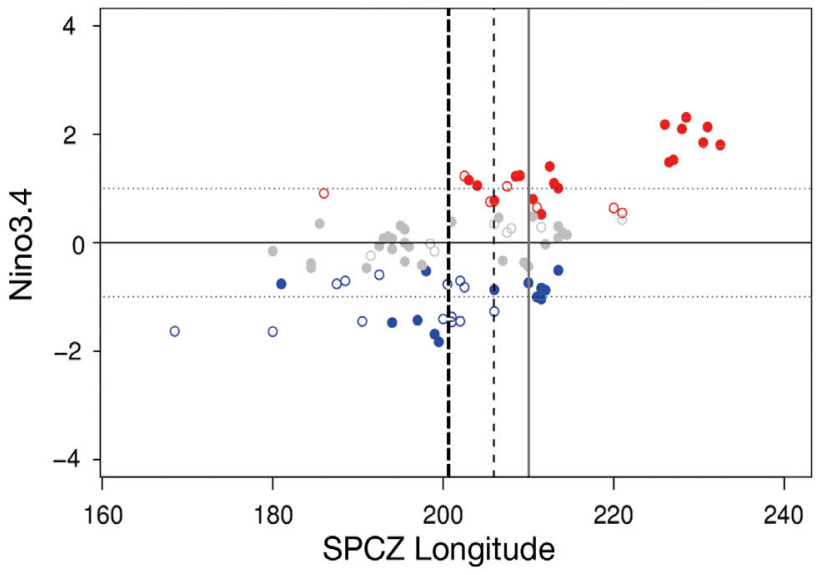

Fig. 8. (a) Scatterplot of 5 yr low-pass-filtered South Pacific Convergence Zone (SPCZ) latitude proxy and Niño3.4 (only DJF months plotted), Niño events, Niña events, neutral events, and Interdecadal Pacific Oscillation positive phase (IPO+) and negative phase (IPO-). The grey line is the latitude of Tahiti $\left(17.5^{\circ} \mathrm{S}\right)$. Dotted lines are drawn at Niño3.4 $=1$. A thin dashed line is plotted at the SPCZ latitude averaged over the IPO+ period, and a thick dashed line is the SPCZ latitude averaged over the IPO- period. (b) Scatterplot of the 5 yr low-pass-filtered SPCZ longitude proxy and Niño3.4 (only DJF months plotted), Niño events, Niña events, neutral events, IPO+ and IPO-. The grey line is the longitude of Tahiti $\left(149.5^{\circ} \mathrm{W}\right)$. Dotted lines are drawn at Niño3.4 $= \pm 0.5$. A thick dashed line is plotted at the SPCZ longitude averaged over the IPO+ period, and a thin dashed line is the SPCZ longitude averaged over the IPO- period

- the impact of strong El Niño during the IPO positive phase that moves the SPCZ further north from Tahiti, which may change the trade wind circulation and favour orographic precipitation on the south coast (windward side)

This linkage could support the view about IPO as a random walk in the ENSO space (Power et al. 2006), but the present study does not address this issue.

\section{CLIMATE CHANGE DETECTION}

The focus here is on the possible impact of any climate trends on Tahiti's annual rainfall. The TOD method was applied to the annual rainfall amounts of the 9 stations for the period 1961-2011. The details of this method are presented in Ribes et al. (2010). As the attribution of long-term trends in the Pacific Ocean to global warming is difficult because of low-frequency variability, the more appropriate term 'climate trend' has been used instead of 'climate change'.

TOD tests the null hypothesis that 'there is no climate trend signal in the observations' against the alternative 'there is a climate trend signal in the observations'. To do so, the method assumes that climate trend has a smooth temporal pattern, which is considered to be a linear trend here. The use of this very simple temporal pattern instead of a more complex smooth pattern may be suboptimal; nevertheless, over short periods like the one investigated here, the nonlinearity of the change is probably not the dominant feature.

Superimposed on this climate trend signal, internal variability in the region of Tahiti is assumed to have a red noise structure (autoregressive process of order $1, \mathrm{AR} 1)$ with a $1 \mathrm{yr}$ lag autocorrelation of 0.2 that was estimated previously using pre-industrial control simulations. As observations are likely influenced by external forcings, internal variability cannot be inferred directly from observed data. Those simulations where external forcings are constant over time (Taylor et al. 2012) are expected to acceptably capture the features of internal variability. In order to consolidate the diagnosis of internal variability, we also used detrended observed time series from the 9 stations. Basically, the $1 \mathrm{yr}$ lag autocorrelation is estimated from the time series of precipitation in the region of Tahiti for each CMIP5 pre-industrial control simulation and from detrended observed time series. The value 0.2 is chosen as it is very close to the median of all the CMIP5 models and the 9 stations.

By regression onto the temporal pattern, the method estimates the spatial distribution of climate trends over all the stations simultaneously.

The temporal evolution of the p-value is shown in Fig. 9a. In concrete terms, the p-value displayed for 1990, for instance, corresponds to the p-value computed over the period 1961-1990. Fig. 9a shows that the null hypothesis tested by TOD is accepted, as the p-value always exceeds 0.05 throughout the period of interest. In addition, Fig. 9b shows there is a slight move towards an orographic spatial pattern, with stations on the windward side getting wetter whereas 


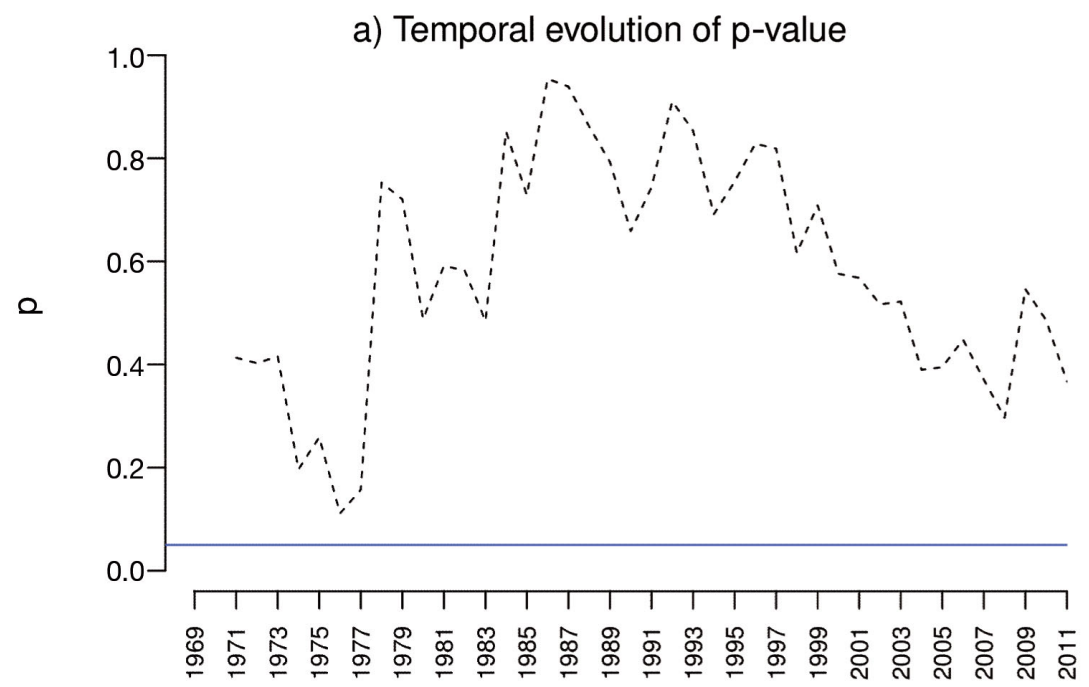

b) Stations detected trends

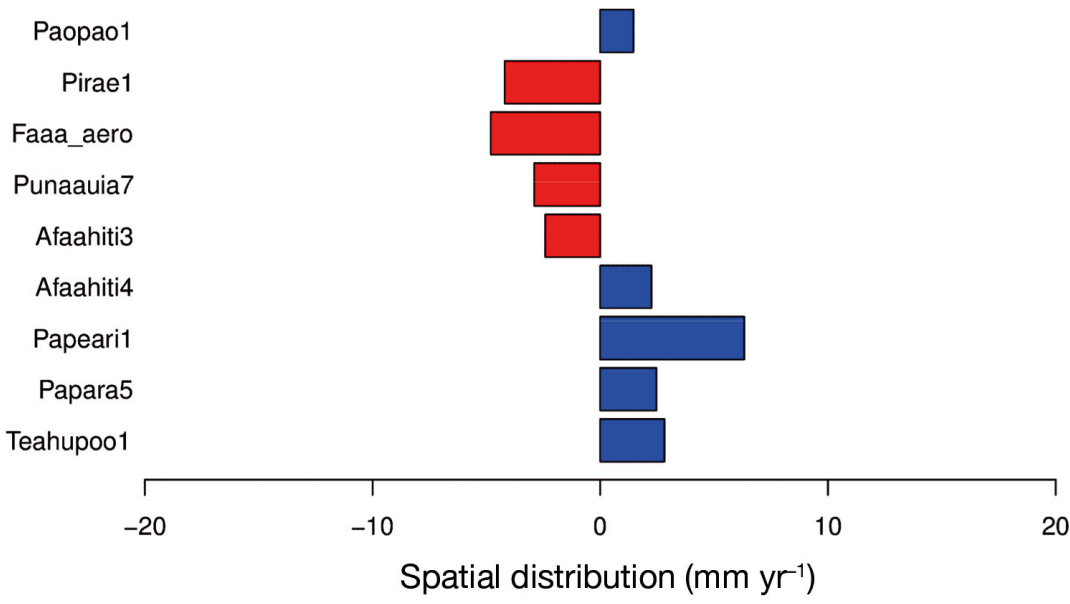

Fig. 9. Temporal optimal detection method detection results: (a) p-value time series, with the horizontal blue line showing the significance threshold of $5 \%$, and (b) g_hat vector (spatial distribution of climate trend signal)

leeward stations tend to become drier, except for Paopao1. This spatial distribution reveals a marked resemblance to the strong El Niño composite (on an annual basis).

Therefore, the apparent precipitation trend detected for 1961-2011 is not statistically significant, leading to the conclusion that there is no evidence of a climate change signature on precipitation. The pvalue drops in 1976-1977 but remains insignificant, suggesting that the trend over the 1961-1977 period is slightly closer to being significant. Considering that it refers to a short period of 16-17 yr, the importance of this drop should not be overestimated. Moreover, the test was also applied assuming a white noise structure for the internal variability, which makes detection easier. In that specific case as well, no significant climate trend was detected, which gives us confidence in our results.

In brief, the apparent orographic signature corresponding to the linear temporal pattern of climate trend (assumed) is not statistically significant. This spatial pattern, recalling the strong El Niño composite (occurring mostly during the IPO positive phase), raises the question of whether this signal is a fingerprint of climate change or simply an artefact related to the IPO. As no climate trend was detected for the period 1961-2011, the question remains unanswered.

TOD was also applied to 6 CMIP5 models, considering grid points corresponding to French Polynesia (not shown). Those models are relatively good at simulating the SPCZ, according to Brown et al. (2013). The detection was performed over the historical period, and no significant trend emerged, which somewhat confirms results from the observations. As for the spatial pattern of the climate trend, there is no consensus among the models. Some of them exhibit a positive trend, while others show negative trends. Robust changes in future ENSO events are still difficult to determine (Collins et al. 2010, Watanabe et al. 2012). Cai et al. (2012) have shown, using coupled models from CMIP3 and CMIP5, that zonal SPCZ events are likely to become more frequent in the 21st century. In the present study, such SPCZ configurations imply an orographic precipitation signal, with wetter southern stations, resembling the spatial pattern obtained with TOD. If the number of extreme SPCZ equatorward migrations is expected to increase in the 21st century (Cai et al. 2012), this spatial pattern could become significant in the near future with respect to the $p$ value threshold.

\section{DISCUSSION}

This study investigated the low-frequency rainfall variability in Tahiti and the possible signature of climate change over 1961-2011. The new homogenized data records provided by the meteorological service of French Polynesia constituted a reliable and suitable database for analysing climate variability and change in this region. 
As the database is available only at monthly timescales, intraseasonal variability was not studied, although precipitation in the region of Tahiti varies on intraseasonal timescales (Griffiths et al. 2003). Matthews (2012), who carried out an analysis of the SPCZ in a multiscale framework, identified the primary modes of SPCZ variability using a spectral analysis of daily anomalous OLR data. He found a large spectral peak at lower interannual frequencies and 2 significant peaks in the intraseasonal and submonthly bands. Through an EOF analysis on OLR data, he highlighted 2 dominant modes: the shifted SPCZ and the enhanced SPCZ mode. For both modes, the mechanism that initiated precipitation was a transient synoptic wave propagating along the subtropical jet, which was then refracted by the basic state toward the westerly duct over the central equatorial Pacific. The occurrence of these events is a stochastic process, the probability of which is affected by lower variability of the basic state such as the MJO and ENSO. These high-frequency events, which last for a few days, consist of a discrete pulse of precipitation along the SPCZ that is strong enough to affect the monthly averages. They were inadequately resolved in our study, appearing on intra-annual scales on the PC1 power spectrum.

The combined effects of the IPO and ENSO on the SPCZ, and consequently on precipitation in Tahiti, were investigated. First, as stated earlier, the SPCZ is displaced further north, on average, during the IPO positive phase (near Tahiti). Then, on interannual time scales, strong El Niño events induced additional major northward displacements of the SPCZ, which moved north of Tahiti. Finally, this anomalous location impacted the circulation of the trade winds, which were deviated and generated positive rainfall anomalies on the windward side of the island.

In the La Niña case, the SPCZ migrations and the impact of the IPO are less evident. This could be explained by the limited amount of available data (especially GPCP) over the IPO negative phase. During La Niña, strong and moderate events are more regularly distributed over the IPO phases. The SPCZ displacements near Tahiti seem less linked to the intensity of the La Niña episode. However, on average, strong La Niña events induce somewhat greater southwestward shifts of the SPCZ than moderate ones. This gap could explain the differences between strong and moderate La Niña composites. The strong La Niña composite in Fig. 7c shows drier conditions at all stations, possibly due to the southwestward departure of the SPCZ. The precipitation response in moderate La Niña (Fig. 7d) indicates an orographic pattern which could be caused by a closer location of the SPCZ, just southwest of Tahiti. For the La Niña case, the SPCZ migrations and the impact of the IPO are less evident than for the El Niño case (Fig. 8).

Regarding the climate change topic, although no climate trend was detected by the TOD method, the decreasing p-value from 1990 to 2011 indicates that this trend could become significant in the near future. The corresponding estimated spatial distribution showed an orographic pattern, with wetter windward stations and drier leeward stations, which recalls the rainfall regime associated with strong El Niño events occurring mostly in the IPO positive phase. It was not clear whether this pattern was really a possible signature of forthcoming climate change or an artefact of a very low-frequency modulation, which is why the term climate trend is more appropriate here than climate change.

Performing the test on a longer data set would help to further support these results. Also, climate change detection applied to CMIP5 models on historical and Representative Concentration Pathway (RCP) runs could provide detection dates and spatial patterns to compare the observation-based results. Also interesting would be to apply the detection method to regional climate models.

\section{CONCLUSIONS}

The conclusions derived from this study are multiple. First of all, the seasonal cycle is the most important source of variance in Tahiti. It is composed of 2 seasons. The wet season, from November to April, is associated with higher rainfall amounts at all stations, consistent with the spatial extension of the SPCZ along its climatological axis. The dry season, from May to October, is characterized by lower rainfall quantities at all stations. Moreover, the SPCZ is most strongly established and closer to Tahiti during this season. Its meridional and zonal shifts, associated with the IPO and ENSO, directly impact Tahitian rainfall amounts and affect water supplies.

After the seasonal cycle had been removed and focus placed on the wet season months, 2 rainfall regimes emerged from the overall analysis. The first regime depicted common behaviour of the stations, suggesting a large-scale precipitation organization over Tahiti. The positive phase of the IPO is known to imply higher air temperature, lower pressure in the central-eastern tropical Pacific and a northward shift of the SPCZ (Folland et al. 2002, Griffiths et al. 2003). In agreement with Folland et al. (2002) and Griffiths 
et al. (2003), it was shown that, during the positive IPO phase, the SPCZ is situated $4^{\circ}$ further north from the negative IPO position and lies very close to Tahiti. The IPO composites indeed showed a general rainfall increase (decrease) during the IPO positive (negative) phase.

The second regime was related to an orographic contrast between windward and leeward stations. This pattern arose from a coherent combination of interactions. The robust mechanism explaining that regime was discussed in Section 4: a positive IPO phase in addition to a strong El Niño event favours orographic precipitation on the southern coasts of Tahiti. The analysis did not identify other clear links concerning low-frequency variability modes and the precipitation anomalies.

Beyond the interannual to interdecadal modulation of rainfall in Tahiti, climate change detection was also addressed in this study. The TOD method (Ribes et al. 2010) applied to annual homogenized rainfall amounts indicated that no climate trend signal was detected. According to the TOD statistical test applied over the $51 \mathrm{yr}$ time series, the climate trend was not significant at the $5 \%$ level.

Since no climate trend was detected in the last half century, the question of climate trend detection slides over to the 21st century. Investigating this issue proved to be a difficult task. The island is too small to be resolved by the CMIP5 global models and is, unfortunately, not covered by any multi-model downscaling exercise such as the CORDEX experiment. Answering this question implied defining a specific strategy, hopefully suitable for similar South Pacific islands, and the present study of rainfall regimes may be useful in such future work.

Acknowledgements. We thank the Meteorological Service of French Polynesia (DIRPF - CER Etude) for performing the homogenization procedure on Tahiti's precipitation records and making the data available. We are grateful to Aurélien Ribes for his help and advice in using the TOD detection algorithm, and to Anthony Jamelot, who provided the topography map. We acknowledge 3 anonymous reviewers and Michel Déqué for their useful comments, which led to improvements to the manuscript.

\section{LITERATURE CITED}

Adler RF, Huffman GJ, Chang A, Ferraro R and others (2003) The version-2 Global Precipitation Climatology Project (GPCP) monthly precipitation analysis (1979present). J Hydrometeorol 4:1147-1167

Brown JR, Power SB, Delage FP, Colman RA, Moise AF, Murphy BF (2011) Evaluation of the South Pacific Convergence Zone in IPCC AR4 climate model simulations of the twentieth century. J Clim 24:1565-1582
Brown JR, Moise AF, Colman RA (2013) The South Pacific Convergence Zone in CMIP5 simulations of historical and future climate. Clim Dyn 41:2179-2197

> Cai W, Lengaigne M, Borlace S, Collins M and others (2012) More extreme swings of the South Pacific convergence zone due to greenhouse warming. Nature 488:365-369

> Caussinus H, Mestre O (2004) Detection and correction of artificial shifts in climate series. JR Stat Soc C 53:405-425

Collins M, An SI, Cai W, Ganachaud A, Guilyardi E, Jin FF, Wittenberg A (2010) The impact of global warming on the tropical Pacific Ocean and El Niño. Nat Geosci 3: 391-397

Folland CK, Renwick JA, Salinger MJ, Mullan AB (2002) Relative influences of the Interdecadal Pacific Oscillation and ENSO on the South Pacific convergence zone. Geophys Res Lett 29(13), doi:10.1029/2001GL014201

Folland CK, Salinger MJ, Jiang N, Rayner NA (2003) Trends and variations in South Pacific island and ocean surface temperatures. J Clim 16:2859-2874

Griffiths GM, Salinger MJ, Leleu I (2003) Trends in extreme daily rainfall across the South Pacific and relationship to the South Pacific Convergence Zone. Int J Climatol 23: 847-869

Hurrell JW, Vincent DG (1987) Significance of the South Pacific Convergence Zone (SPCZ) in the energy budget of the southern hemisphere tropics. Mon Weather Rev 115:1797-1801

Jovanovic B, Braganza K, Collins D, Jones D (2012) Climate variations and change evident in high-quality climate data for Australia's Antarctic and remote island weather stations. Aust Meteorol Oceanogr J 62:247-261

Kiladis GN, Von Storch H, Loon H (1989) Origin of the South Pacific convergence zone. J Clim 2:1185-1195

Laurent V, Maatuaiahutapu K, Maiau J, Varney P (2004) Atlas climatologique de la Polynésie Française. MétéoFrance, Direction Interrégionale de Polynésie Française, Punaauia

> Lintner BR, Neelin JD (2008) Eastern margin variability of the South Pacific convergence zone. Geophys Res Lett 35:L16701, doi:10.1029/2008GL034298

Lorrey A, Dalu G, Renwick J, Diamond H, Gaetani M (2012) Reconstructing the South Pacific convergence zone position during the presatellite era: a La Niña case study. Mon Weather Rev 140:3653-3668

> Matthews AJ (2012) A multiscale framework for the origin and variability of the South Pacific Convergence Zone. QJR Meteorol Soc 138:1165-1178

> Matthews AJ, Li HYY (2005) Modulation of station rainfall over the western Pacific by the Madden-Julian oscillation. Geophys Res Lett 32:L14827, doi:10.1029/2005GL 023595

- McGree S, Whan K, Jones D, Alexander LV and others (2014) An updated assessment of trends and variability in total and extreme rainfall in the western Pacific. Int $\mathrm{J}$ Climatol 34:2775-2791

> Meehl GA (1987) The annual cycle and interannual variability in the tropical Pacific and Indian Ocean regions. Mon Weather Rev 115:27-50

Murphy BF, Timbal B (2008) A review of recent climate variability and climate change in southeastern Australia. Int J Climatol 28:859-879

Murphy BF, Power S, McGree S (2014) The varied impacts of El Niño-Southern Oscillation on Pacific island climates. J Clim 27:4015-4036

Parker D, Folland C, Scaife A, Knight J, Colman A, Baines P, 
Dong B (2007) Decadal to multidecadal variability and the climate change background. J Geophys Res Atmos 112:D18115, doi:10.1029/2007JD008411

Power SB, Kociuba G (2011) The impact of global warming on the Southern Oscillation Index. Clim Dyn 37:1745-1754

Power SB, Smith IN (2007) Weakening of the Walker Circulation and apparent dominance of El Niño both reach record levels, but has ENSO really changed? Geophys Res Lett 34:L18702, doi:10.1029/2007GL030854

Power S, Haylock M, Colman R, Wang X (2006) The predictability of interdecadal changes in ENSO activity and ENSO teleconnections. J Clim 19:4755-4771

Rasmusson EM (1985) El Niño and variations in climate: large-scale interactions between the ocean and the atmosphere over the tropical Pacific can dramatically affect weather patterns around the world. Am Sci 73: 168-177

Rayner NA, Parker DE, Horton EB, Folland CK and others (2003) Global analyses of sea surface temperature, sea ice, and night marine air temperature since the late nineteenth century. J Geophys Res Atmos 108:4407, doi:10. 1029/2002JD002670

Ribes A, Azaïs JM, Planton S (2010) A method for regional climate change detection using smooth temporal patterns. Clim Dyn 35:391-406

Salinger MJ, Renwick JA, Mullan AB (2001) Interdecadal Pacific Oscillation and south Pacific climate. Int J Climatol 21:1705-1721

Salinger MJ, McGree S, Beucher F, Power SB, Delage F (2014) A new index for variations in the position of the South Pacific convergence zone 1910/11-2011/2012. Clim Dyn 43:881-892

Editorial responsibility: Balaji Rajagopalan, Boulder, Colorado, USA
Streten NA (1973) Some characteristics of satellite-observed bands of persistent cloudiness over the Southern Hemisphere. Mon Weather Rev 101:486-495

Takahashi K, Battisti DS (2007) Processes controlling the mean tropical Pacific precipitation pattern. II. The SPCZ and the southeast Pacific dry zone. J Clim 20:5696-5706

Taylor KE, Stouffer RJ, Meehl GA (2012) An overview of CMIP5 and the experiment design. Bull Am Meteorol Soc 93:485-498

- Trenberth KE (1976) Spatial and temporal variations of the Southern Oscillation. QJR Meteorol Soc 102:639-653

> Trenberth KE (1991) Storm tracks in the Southern Hemisphere. J Atmos Sci 48:2159-2178

- Vincent DG (1994) The South Pacific convergence zone (SPCZ): a review. Mon Weather Rev 122:1949-1970

> Vincent EM, Lengaigne M, Menkes CE, Jourdain NC, Marchesiello P, Madec G (2011) Interannual variability of the South Pacific Convergence Zone and implications for tropical cyclone genesis. Clim Dyn 36:1881-1896

Watanabe M, Kug JS, Jin FF, Collins M, Ohba M, Wittenberg AT (2012) Uncertainty in the ENSO amplitude change from the past to the future. Geophys Res Lett 39: L14702, doi:10.1029/2012GL052013

Whan K, Alexander LV, Imielska A, McGree S and others (2014) Trends and variability of temperature extremes in the tropical Western Pacific. Int J Climatol 34:2585-2603

> Widlansky MJ, Webster PJ, Hoyos CD (2011) On the location and orientation of the South Pacific Convergence Zone. Clim Dyn 36:561-578

> Widlansky MJ, Timmermann A, Stein K, McGregor S and others (2013) Changes in South Pacific rainfall bands in a warming climate. Nat Clim Change 3:417-423

Submitted: March 13, 2014; Accepted: January 19, 2015 Proofs received from author(s): April 24, 2015 